Proceedings of the Annual Scientific Meeting of the International Medical Society of Paraplegia held in Toronto from 4 to 6 August 1976 (Part I)

\title{
PROBLEMS IN THE RADIOLOGICAL INTERPRETATION OF THE X-RAY APPEARANCE OF THE BLADDER WALL AND BLADDER NECK OBTAINED ON MICTURATING CYSTO-URETHROGRAPHY IN PATIENTS WITH NEUROGENIC BLADDERS
}

\author{
By A. T. Scher, M.B., Ch.B., D.M.R.D. \\ Spinal Injuries Centre, Conradie Hospital, Cape Town, South Africa
}

Abstract. The technique in performing micturating cysto-urethrography is described. Technical difficulties in obtaining micturating films and positioning of paraplegic patients are discussed. A previous author has stated that radiological assessment of the bladder neck is of no value. Analysis of intravenous pyelograms (IVP) and micturating cystourethrogram (MCUG) on 7I paraplegic patients confirms that there is no correlation between the diameter of the bladder neck and the presence of pathological renal changes or vesico-ureteric reflux.

Difficulties in the radiological assessment of bladder capacity and contour due to marked differences in appearance on MCUG and IVP are discussed.

Key words: Cysto-urethrography; Radiography; Bladder neck obstruction.

\section{Introduction}

URINARY tract complications are well recognised as being the most serious danger to the paraplegic patient. We have therefore in the Spinal Injuries Unit endeavoured to obtain an intravenous pyelogram (IVP) and micturating cystourethrogram (MCUG) on every paraplegic patient once a year. Correlation of the IVP and MCUG which are done within a short interval of each other reveals certain difficulties in the radiological interpretation of the appearances of the bladder wall and bladder neck.

\section{Technique of Performing the Micturating Cysto-urethrogram}

A control film of the pelvis is exposed. The bladder is filled with contrast material using a Foley's catheter and a glass funnel. The funnel is held at a height of $15 \mathrm{~cm}$ and an X-ray film is exposed, the funnel is then raised to a height of 30 $\mathrm{cm}$, and a second X-ray is obtained. The patient is placed in a steeply oblique position, the catheter is removed and a micturating film is then obtained. At the conclusion of the examination a post-micturation film is also obtained.

\section{Technical Difficulties in Performing the Examination}

In 3 I out of I03 MCUGs the urethra was not adequately visualised. This is due to the following factors: ( $a$ ) the patient is unable to micturate; or $(b)$ due to the patient micturating so rapidly that the X-ray could not be exposed rapidly enough.

Another problem is the difficulty in maintaining the patient in a steeply oblique position during the procedure. This is of considerable importance since in the antero-posterior or slightly oblique projection the urethro-vesical junction is 
obscured by superimposition of the most dependent portion of the bladder which lies behind the symphysis pubis and is inferior to the urethro-vesical junction.

The use of cine-radiography or videotape recording would of course be of considerable assistance in excluding vesico-ureteric reflux, in obtaining visualisation of the bladder neck at all stages of voiding and in visualising the urethra in those patients who have no control of their micturition and micturate very rapidly. These facilities are unfortunately not available at present. Some units are not in favour of the technique as described above, which of course requires catheterisation of the patient and the consequent risk of introducing infection. These workers therefore prefer to use a Prograde technique, i.e. injection of contrast medium as for an intravenous pyelogram and then endeavouring to obtain micturating films.

Whilst it is desirable to avoid catheterising a paraplegic patient the limitation of the Prograde technique is of course the inability to assess vesico-ureteric reflux since the ureters are filled with contrast medium. Further, it is often difficult to obtain a voiding film and since the patient's bladders fill at different rates the examination may be time-consuming since one is forced to wait for the bladder to fill.

Another technique described by McCall (1974) using a retrograde technique does not avoid the danger of instrumentation to the urethra and would not appear to give a physiologically normal pattern when compared to the normal micturating examination.

\section{Information Gained from Micturating Cysto-urethrography}

The following information is ideally obtained: ( $\mathrm{I}$ ) the bladder contour, i.e. trabeculation of the bladder wall, presence of diverticulae and general shape of the bladder; (2) the capacity of the bladder; (3) the presence or absence of vesicoureteric reflux; (4) reflux into the seminal vesicles and prostatic ducts; (5) the appearance of the bladder neck; (6) evidence of external sphincter spasm; (7) the appearance of the anterior urethra particularly as regards fistulae and peri-urethral diverticulae; and (8) the control film reveals evidence of calculus disease and also incidentally of ectopic bone in the soft tissues of the pelvis and proximal femorae.

\section{Problems in Radiological Interpretation}

\section{Assessment of the Bladder Neck}

The role of the bladder neck and external sphincter in the neurogenic bladder has been the subject of considerable research and literature, and the consensus of opinion appears to be that the external sphincter is of major importance in causing obstruction to bladder emptying in the neurogenic bladder. Nevertheless attention is still paid to the bladder neck and the bladder neck is very often reported on radiologically as being narrow, normal or dilated.

Shopfner (1967) has stated that the radiological features are of no value in a diagnosis of bladder neck obstruction. He points out that the bladder neck diameter varies with the age and size of the patient and that further there is a sizable variation in different individuals of the same size and age and in the same individual during the various stages of voiding. He also points out that a basic principle in luminal obstruction is that a constriction must be the narrowest portion of a tube before it can be considered an obstructive point. The bladder neck is not the narrowest point in the urethra in any patient being always as wide as the normal urethral 
narrowings at the urogenital diaphragm (membranous urethra) and suspensory ligament of the penis in the male, and the urogenital diaphragm in the female.

Shopfner (1968) in another paper describes the anatomy of the base of the bladder stating that there is a base plate which is a unit both anatomically and functionally. This base plate is flat while the bladder is relaxed, but is forced out of its normal flat position into a cone formation on micturition to form the 'trigonal canal'. This canal is continuous with and simulates the urethra and a 'pseudo bladder neck' is created between the bladder wall and bladder base plate. It is essential that the 'pseudo bladder neck' is not interpreted as the urethro-vesical junction and he feels that the term bladder neck as referring to the urethro-vesical junction should be abandoned. In the light of these observations by Shopfner, analysis of satisfactory MCUGs and IVPs performed on 7I patients was undertaken. In all cases the MCUG and IVP were obtained within a short period of each other. Patients who had undergone surgery to the bladder neck or external sphincter were not included in this series. All the patients in this series had sustained traumatic spinal cord injury with consequent paraplegia or tetraplegia. The cases were unselected, comprising both complete and incomplete lesions and varying in duration from 3 months to 20 years since the date of injury.

Initially attempts were made to classify the radiographic bladder neck according to a classification used by Ascoli (1967) who divided his patients into five grades according to the radiological appearance of the bladder neck, but this was abandoned since difficulties in grading the bladder neck, particularly between Grades I and 2 as described by Ascoli, were soon evident. Measurement of the radiographic bladder neck in millimetres on voiding in the steeply oblique position was therefore performed.

Reference to Table I shows that the majority (6o per cent) of patients have bladder necks ranging from 8 to $15 \mathrm{~mm}$ in diameter. It is of interest that there does not appear to be any correlation between the size of the bladder neck and the presence of pathological changes (pyelonephritis and hydronephrosis) in the kidneys. It can be seen in Table II that in 56 per cent of cases with pathological renal changes on IVP, i.e. the majority of patients, the bladder neck was found to be in the intermediate range of 8 to $15 \mathrm{~mm}$. There was no higher incidence of renal pathology in patients with a narrow bladder neck nor was there any lesser degree of renal pathology in patients with a wide bladder neck. Further analysis of the patients demonstrating vesico-ureteric reflux on MCUG did not demonstrate any higher incidence of reflux in patients with narrow bladder necks, the majority of patients with vesico-ureteric reflux having bladder necks in the intermediate range.

TABLE I

Bladder neck diameter

\begin{tabular}{|c|c|c|c|c|c|}
\hline \multicolumn{2}{|c|}{ 3-7 mm } & \multicolumn{2}{|c|}{$8-15 \mathrm{~mm}$} & \multicolumn{2}{|c|}{ I6-25 mm } \\
\hline $\begin{array}{l}\text { No. of } \\
\text { patients }\end{array}$ & Per cent & $\begin{array}{l}\text { No. of } \\
\text { patients }\end{array}$ & Per cent & $\begin{array}{l}\text { No. of } \\
\text { patients }\end{array}$ & Per cent \\
\hline 19 & 26 & 42 & 60 & I0 & I 4 \\
\hline
\end{tabular}




\section{TABLE II}

Number and percentage of patients having pathological renal changes on IVP for each category of bladder neck size

\begin{tabular}{|c|c|c|c|c|c|}
\hline \multicolumn{2}{|c|}{ 3-7 mm } & \multicolumn{2}{|c|}{$8-15 \mathrm{~mm}$} & \multicolumn{2}{|c|}{ I6-25 mm } \\
\hline $\begin{array}{l}\text { No. of } \\
\text { patients }\end{array}$ & Per cent & $\begin{array}{l}\text { No. of } \\
\text { patients }\end{array}$ & Per cent & $\begin{array}{l}\text { No. of } \\
\text { patients }\end{array}$ & Per cent \\
\hline 5 & 20 & I4 & 56 & 6 & 24 \\
\hline
\end{tabular}

\section{Difficulties in the Assessment of the Bladder Contour and Bladder Capacity}

It has been noted in many cases that whereas on micturating cystourethrography the bladder is shown to be markedly contracted with a diminished capacity and trabeculation of its wall both at rest and on voiding, the same patient's bladder on IVP performed either before or after the MCUG will present a normal appearance, i.e. no abnormality of the bladder wall nor any decrease in capacity.

This is presumably due to the irritant effect of the contrast medium on the bladder wall and retrograde introduction of fluid into the bladder causing reflex contraction of the bladder, but if the MCUG is used as the only criterion for assessment of the bladder contour and capacity, an erroneous report of a bladder of diminished capacity with a trabeculated wall of the upper motor-neurone type will be made. An illustrative case is shown in Figures I and 2.

\section{Conclusions}

While micturating cysto-urethrography is of considerable assistance in assessment of the neurogenic bladder as regards the exclusion of vesico-ureteric reflex, the presence or absence of calculi and diverticulae and in the visualisation of the urethra, it would appear from the above analysis that radiological interpretation of the diameter of the bladder neck is of little value. Further assessment of the bladder capacity and contour judged on MCUG only would also appear to be erroneous in some cases.

\section{RÉSUMÉ}

On a décrit la technique de cystouréthrographie en miction. On discute les difficultés techniques d'obtenir les films de miction et la position des patients paraplégiques. Un auteur précédent a noté que la détermination radiologique du cou de la vessie n'a pas de valeur. L'analyse des Pyélogrammes intraveineuses et des cysto-uréthrogrammes en miction de 7I patients confirme qu'il n'y a pas de correlation entre le diamétre du cou de la vessie et entre la presence de changments pathologiques et rénals ou le reflux á la jonction de la vessie et de l'uretére.

L'auteur discute aussi les difficultés de la détermination radiologique de la capacité et du contour de la vessie á cause des différences.

\section{ZUSAMMENFASSUNG}

Die Technik der 'micturating cysto-urethrography' wird beschrieben. Es werden technische Schwierigkeiten im Erlangen der 'micturating' Filme und bei der Lagerung des 


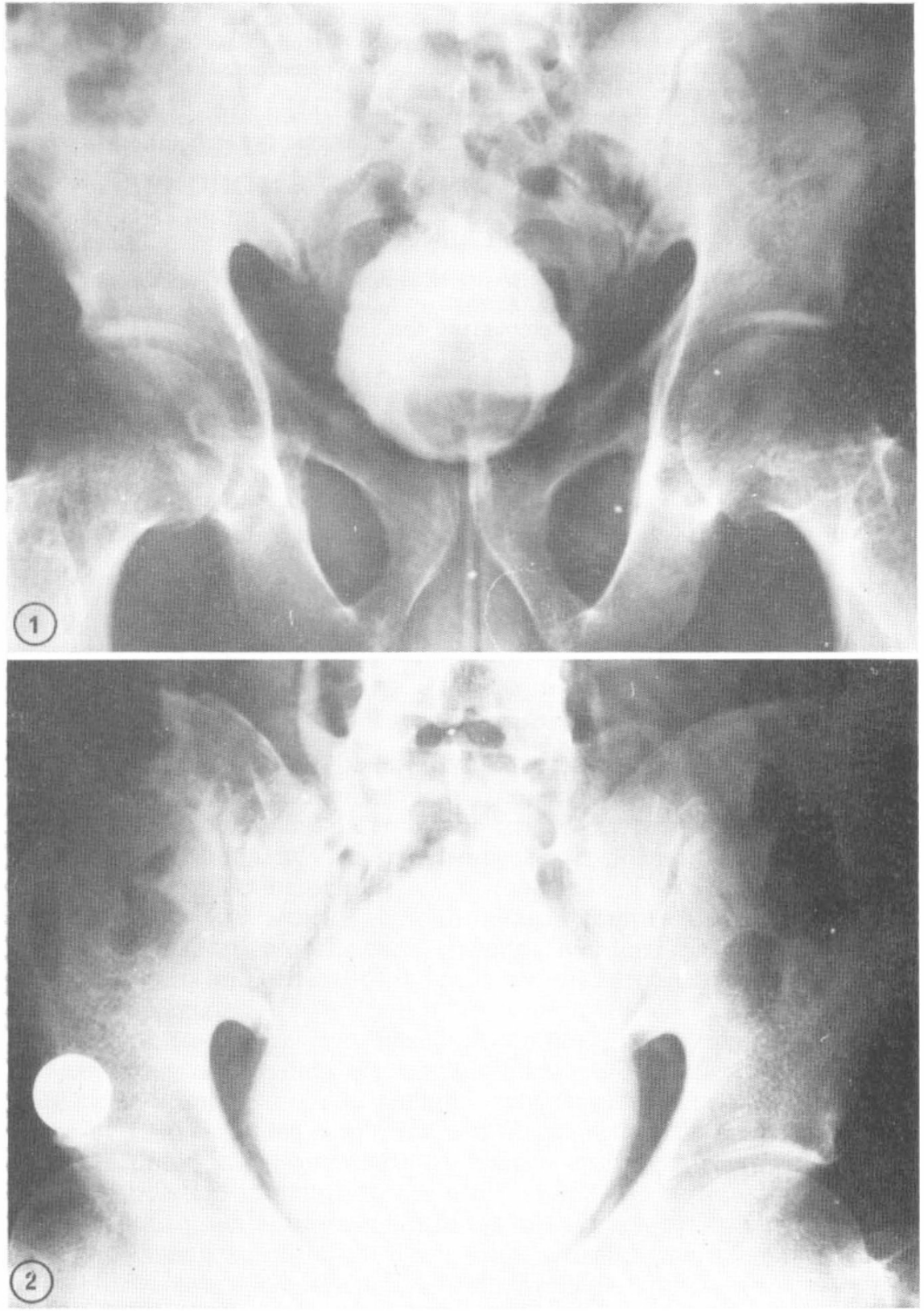

FIG. I

Cystogram on a paraplegic patient demonstrating a bladder of apparently decreased capacity and having a trabeculated wall.

Fig. 2

The same patient's bladder shown on IVP performed 48 hours prior to cystogram. Note that the bladder now appears to be of normal capacity and has a normal outline without trabeculation. 
paraplegischen Patienten besprochen. Ein früherer Author stellte fest, dass eine radiologische Untersuchung des Blasenhalses von keiner Bedeutung ist. Die Analysen der IVP und MCUGs von 7I paraplegischen Patienten bestätigen, dass kein Zusammenhang zwischen dem Durchmesser des Blasenhalses und des Vorhandenseins von pathologischen Nierenveränderungen oder 'vesico-ureteric reflux' besteht.

Bei radiologischen Untersuchung der Blasenaufnahmefähigkeit und der Blasenumrisse bestehen bestimmte Unterschiede. Diese unterchiedlichen Erscheinungen stellen ein Problem dar und wurden erwähnt.

\section{REFERENCES}

Ascoli. (1967). Radiological study of the vesical neck in paraplegia secondary to Spinal cord injury. Int. F. Paraplegia, 4, 4: 235.

MCCALL. (1974). The radiologic assessment of the lower urinary tract in paraplegics: new method. F. Can. Assoc. Radiologists, 25, I: 34.

SHOPFNER. (1967). Roentgenological evaluation of bladder neck obstruction. Amer. $\mathcal{F}$. Roentgenology, 100, I: I62.

SHOPFNER \& HUTCH. (I968). The normal urethrogram. Radiologic Clinics of North America, 6, 2: 165 . 